\title{
Experiências em atenção primária em 25 anos da Revista Ciência \& Saúde Coletiva: uma revisão de literatura
}

\author{
Primary care experiences in 25 years of Journal Ciência \& Saúde \\ Coletiva: a review of the scientific literature
}

Luiz Felipe Pinto (http://orcid.org/0000-0002-9888-606X) 1,2

Zulmira Maria de Araújo Hartz (http://orcid.org/0000-0001-9780-9428) ${ }^{2}$

${ }^{1}$ Programa de PósGraduação em Atenção Primária à Saúde, Faculdade de Medicina, Universidade Federal do Rio de Janeiro. Av. Presidente Vargas 2863, Cidade Nova. 20210-030 Rio de Janeiro RJ Brasil. felipepinto.rio@ medicina.ufrj.br

${ }^{2}$ Instituto de Higiene e Medicina Tropical, Universidade Nova de Lisboa. Lisboa Portugal.

\begin{abstract}
The term "basic care" is restricted to a few countries like Brazil. Since the 1978 Alma-Ata Conference, "primary health care" (PHC) has been used to designate care at the first level. The paper summarizes the experiences of evaluation in primary health care, based on the review of the set of manuscripts published by Journal Ciencia \& Saúde Coletiva. A bibliographic search was made in the SciELO database in the 1996-2020 period. Several descriptors were selected in the spectrum of evaluation and basic care/primary care. The reviewed studies suggest the existence of two analytical periods over the 25 years of the Journal. The first, characterized by the 1996-2010 studies, had the studies of structure/process/results by Donabedian as its predominant theory. The second, from 2011-2020, was Billings' theories on Ambulatory Care Sensitive Conditions (ACSC) and Starfield's PHC attributes. The main dimensions presented in the studies refer to evaluations with a quantitative approach and are induced by the policies and public consultations of the Ministry of Health, and instruments referenced by it.
\end{abstract}

Key words Health assessment, Primary Health Care, Brazil
Resumo O termo "atenção básica” tem seu uso restrito a poucos países como o Brasil. No mundo, desde a Conferência de Alma-Ata de 1978, o termo "atenção primária à saúde" (APS) é utilizado para designar o cuidado no primeiro nível de atenção. $O$ artigo sintetiza as experiências de avaliação em atenção primária à saúde, a partir da revisão do conjunto de manuscritos publicados pela Revista Ciência \& Saúde Coletiva. Fez-se busca bibliográfica na base de dados SciELO desse periódico, no período 1996-2020. Selecionaram-se diversos descritores no espectro da avaliação e atenção básical atenção primária. Os estudos revisados sugerem a existência de dois períodos analíticos ao longo dos 25 anos da Revista. O primeiro, caracterizado pelos estudos de 1996-2010, teve como teoria predominante, os estudos de avaliação de estrutural processo e resultados a partir de Donabedian. $O$ segundo, de 2011-2020, as teorias de Billings sobre condições sensíveis à APS e de atributos da APS de Starfield. As principais dimensões apresentadas nos estudos referem-se a avaliações com abordagem quantitativa e induzidas pelas politicas e consultas públicas do Ministério da Saúde, além de instrumentos referendados por esse.

Palavras-chave Avaliação em saúde, Atenção Primária à Saúde, Brasil 


\section{Introdução}

O termo "atenção básica” ou "atenção básica à saúde" tem seu uso a poucos países como o Brasil. No mundo, desde a Conferência de Alma-Ata de 1978, no Cazaquistão, o termo "atenção primária à saúde" ("cuidados primários de saúde", em Portugal; "atención primária de salud" em espanhol, e "primary health care" em inglês) é utilizado para designar o cuidado no primeiro nível de atenção, que pode ser definido tal como Starfield ${ }^{1}$ como aquele que se caracteriza por quatro atributos essenciais: acesso de primeiro contato, longitudinalidade, coordenação do cuidado e integralidade. Diferencia-se ainda quando além desses, estão presentes também outros três atributos, denominados, atributos derivados: orientação familiar, comunitária e competência cultural.

No Brasil, a então chamada "atenção básica em saúde" contemplou ao longo das décadas qualquer serviço ambulatorial prestado em postos e centros de saúde. Por exemplo, historicamente, o IBGE desde a década de 1970 foi o primeiro órgão a sistematizar nacionalmente uma análise dos estabelecimentos de saúde sem internação (denominação dada por este órgão aos postos e centros de saúde com cuidado ambulatorial) em seu inquérito administrativo intitulado "Pesquisa de Assistência Médico-Sanitária - AMS"2. O Brasil se destaca no cenário mundial por oferecer um dos maiores sistemas públicos de cobertura universal do mundo, reconhecido por diversos autores ${ }^{3}$ e baseado na atenção primária à saúde. No país, a oferta de ações, serviços e procedimentos é desenvolvida por uma rede de unidades de atenção primária à saúde (postos e centros de saúde, unidades de saúde familiar) de responsabilidade majoritariamente municipal. Nessa modalidade de prestação de serviços existiam até abril/2020, 47 mil estabelecimentos de saúde em praticamente todos os 5.570 municípios e Distrito Federal ${ }^{4}$. A relevância e capilaridade dessa rede de APS demonstrou sua importância ao acolher no $1^{\circ}$ semestre de 2020 as pessoas com sintomas leves de síndrome gripal, no contexto da pandemia do novo coronavírus COVID-195. Segundo o $\mathrm{IBGE}^{6}$ em sua PNAD COVID-19, dos 24 milhões de brasileiros com sintomas de síndrome gripal em maio/2020, 84,3\% não buscaram unidade de saúde. Dentre esses que não procuraram unidade de saúde e ficaram em casa, mais de 500 mil receberam visita de algum profissional de equipe de saúde da família ou agente comunitário de saúde. Portanto, a APS ampliou em parte o acesso da população ao cuidado, apoiando a operacionalização das ações de vigilância em saúde dos casos leves e seus contatos, minimizando o afluxo de pacientes aos serviços de urgência e emergência, contribuindo para minimizar o colapso do SUS durante a pandemia.

Na Revista Ciência \& Saúde Coletiva, em 1998, Hartz e Pouvourville ${ }^{7}$, depois Hartz ${ }^{8}$, em 1999, em 2002, Bodstein ${ }^{9}$ e também Costa e Pinto ${ }^{10}$ foram os primeiros autores a abordar, debater e investigar a questão das experiências de avaliação em saúde (inicialmente como avaliação de programas) e da projeção da atenção básica na agenda da saúde pública brasileira, respectivamente em 1999 e 2002. Posteriormente, dezenas de estudos foram publicados pela Revista descrevendo, analisando e avaliando experiências locais, regionais e internacionais na área da atenção primária à saúde. A proposta desse texto é refletir, através de uma revisão da literatura as contribuições desses autores e as temáticas predominantes abordadas pelos mesmos na contribuição para a Saúde Coletiva brasileira, sem pretender esgotar o debate.

\section{Metodologia}

Buscamos responder às seguintes perguntas: (i) como os autores da Revista Ciência \& Saúde Coletiva abordaram a temática da avaliação em saúde desde 1996, partindo do Programa de Agentes Comunitários de Saúde (PACS), do Programa de Saúde da Família (PSF), para a atenção básica, para a Estratégia de Saúde da Família até chegar à atenção primária à saúde?, (ii) atenção básica e atenção primária à saúde foram analisadas como sinônimos, conceitos construídos ou em construção nos artigos sobre avaliação em saúde publicados pela Revista Ciência \& Saúde Coletiva nos últimos 25 anos?, (iii) a criação da Secretaria Nacional de Atenção Primária à Saúde (SAPS) pelo Ministério da Saúde do Brasil em 2019, à luz das questões anteriores, definem uma mudança no paradigma para a avaliação em saúde nos últimos 25 anos ou trata-se apenas de mudança semântica na publicação dos artigos posteriores?

O conjunto de estudos analisados foi identificado através de pesquisa bibliográfica integrativa, de forma a sistematizar e seguir a mesma metodologia de Assis et al. ${ }^{11}$. 


\section{Critérios de busca}

Utilizamos como única fonte a base de dados da Revista Ciência \& Saúde Coletiva no SciELO, para o período completo de suas edições até seus 25 anos, ou seja, o período de setembro/1996 até abril/2020, considerando quaisquer dos índices indexados nos idiomas português ou inglês, com as chaves de busca "E" ou "AND" e as seguintes combinações de palavras-chave: "avaliação e atenção primária", "Atenção Primária à Saúde e avaliação de serviços de saúde" "Atenção Primária à Saúde e qualidade da assistência à saúde", "avaliação da atenção básica", "serviços básicos de saúde”, "avaliação e cuidados de saúde primários", "avaliação em Saúde e Saúde da Família”, "Avaliação e Saúde da Família", "Avaliação e agentes comunitários de saúde", "Avaliação e Programa de Saúde da Família”.

Embora o termo "avaliação" não estivesse associado aos termos "serviços básicos de saúde", "atenção primária à saúde e pagamento por desempenho", "atenção primária à saúde e pesquisa em serviços de saúde”, “atenção primária à saúde e internações por condições sensíveis à atenção básica/primária”, "Programa de Saúde da Família”, "Agente comunitário de saúde”, “agentes comunitários”, optamos por incluí-lo na busca inicial para uma leitura abrangente e captura de todos os resumos, tendo em vista, que a área da avaliação de programas, com o então PACS e PSF, terem sido no final das décadas de 1990/2000, analisadas sob a perspectiva descritiva e epidemiológica.

Elaboramos no Excel, um extenso banco de dados contendo variáveis descritoras de cada um dos artigos levantados para a realização da pesquisa bibliográfica, realizada e aqui analisada em duas etapas e em parte dos resultados, estratificamos a análise em dois grupos, artigos publicados até $2010 \mathrm{x}$ artigos publicados depois de 2010 . Isso porque depois de 2010 , a revista passou a ter periodicidade mensal e gostaríamos de medir o efeito dessa mudança na publicação dos artigos.

$\mathrm{Na} 1^{\text {a }}$ etapa, encontramos relacionados na base, um total 201 artigos, para os quais foram lidos os resumos e pré-selecionamos 181, após a extração de textos duplicados e de acordo com os critérios de inclusão e exclusão. No primeiro caso, incluímos os textos: (i) com foco na avaliação em saúde simultaneamente à abordagem na atenção ambulatorial/básica/atenção primária, (ii) com abordagem de programas de Saúde, atenção básica, cuidados básicos de saúde, atenção primária associados à avaliação de programas, políticas ou serviços de saúde. Já entre os critérios de exclusão, consideramos: (i) estudos de revisão de literatura, (ii) avaliações em saúde, sem foco na atenção básica/atenção primária, (iii) artigos duplicados, (iv) foco específico em análises descritivas sem associação com avaliação, (v) idiomas não acessíveis (outros além do português, inglês, espanhol e francês).

$\mathrm{Na} 2^{\mathrm{a}}$ etapa, após analisar os resumos, eliminaram-se 115 artigos, especialmente aqueles cujas palavras-chave iniciais não estavam relacionadas simultaneamente e direta ou indiretamente ao objeto da revisão sistemática (avaliação em saúde e atenção básica/atenção primária). Portanto, a amostra final da $2^{\text {a }}$ etapa para a qual foi realizada a leitura completa dos textos foi composta por 65 artigos (Tabela 1).

\section{Resultados da $1^{\text {a }}$ etapa: perfil do universo de artigos selecionados para a revisão bibliográfica $(\mathrm{N}=181)$}

Uma questão importante a ser destacada é que a Revista Ciência \& Saúde Coletiva desde sua primeira edição em setembro de 1996 teve um enorme crescimento na submissão de artigos, e com isso, ao longo do tempo, sua periodicidade foi mudando. Passou de dois números anuais entre 1996 e 2001, para três edições anuais entre 2002 e 2006, seguindo-se para duas edições entre 2007 e 2010, até finalmente tornar-se uma revista mensal. Isso ajuda a explicar o porquê observou-se na busca realizada para esse estudo, um maior número de artigos no período pós-2010. Mesmo assim, como veremos adiante, proporcionalmente ao número total de textos publicados, destacam-se os anos de 2006 (edição 11.3) e 2020 (edição 25.4) (Gráfico 1); o ano de 2020 foi considerado de forma parcial, isto é, até o mês de abril. Uma explicação que vemos é que esses dois anos, refletem, respectivamente os anos em que foram instituídas a Política Nacional de Atenção Básica (PNAB, $1^{\text {a }}$ edição) e 2020. Esse último ano configura-se o ano seguinte à criação em 2019, de uma Secretaria Nacional de Atenção Primária à Saúde (SAPS) no âmbito do Ministério da Saúde e do novo modelo federal de financiamento das Equipes de Saúde da Família. Por outro lado, outros números especiais da Revista tiveram uma concentração de artigos publicados na temática da avaliação e atenção primária à saúde, com ênfase nos números 16.11 (2011) e 22.3 (2017).

Buscamos também alguns termos pré-definidos em cada um dos artigos completos $(\mathrm{N}=$ 181), para traçar uma análise ao longo dos 25 
Tabela 1. Revisão bibliográfica sobre avaliação e atenção primária à saúde: artigos eliminados pelo resumo e amostra final pelos critérios de inclusão e exclusão. Revista Ciência \& Saúde Coletiva, 1996-2020.

\begin{tabular}{|c|c|c|c|}
\hline \multirow[b]{2}{*}{ Palavras-chave pesquisadas } & \multicolumn{3}{|c|}{$\mathrm{N}^{\circ}$ de estudos } \\
\hline & $\begin{array}{l}\text { Pré- } \\
\text { selecionados } \\
(\mathrm{N})\end{array}$ & $\begin{array}{l}\text { Eliminados } \\
\text { pelo } \\
\text { resumo }(e)\end{array}$ & $\begin{array}{l}\text { Revisão pelos } \\
\text { critérios gerais de } \\
\text { inclusão }(n=N-e)\end{array}$ \\
\hline $\begin{array}{l}\text { 01. Agente comunitário de saúde, agentes comunitários, } \\
\text { agentes comunitários de saúde/Programa de Saúde da } \\
\text { Família }\end{array}$ & 44 & 40 & 4 \\
\hline $\begin{array}{l}\text { 02. Atenção básica, atenção básica à saúde, atenção básica } \\
\text { em saúde, atenção básica de saúde }\end{array}$ & 55 & 42 & 13 \\
\hline 03. Cuidados de saúde primários & 7 & 4 & 3 \\
\hline 04. Basic health services/primary health care & 4 & 2 & 2 \\
\hline 05. Serviços básicos de saúde & 4 & 4 & 0 \\
\hline 06. Atenção primária à saúde e pagamento por desempenho & 1 & 0 & 1 \\
\hline $\begin{array}{l}\text { 07. Atenção primária à saúde e pesquisa em serviços de } \\
\text { saúde }\end{array}$ & 1 & 0 & 1 \\
\hline $\begin{array}{l}\text { 08. Atenção primária à saúde e internações por condições } \\
\text { sensíveis à atenção básica/primária }\end{array}$ & 4 & 0 & 4 \\
\hline 09. Avaliação da atenção básica & 4 & 0 & 4 \\
\hline $\begin{array}{l}\text { 10. Avaliação de desempenho ou avaliação de desempenho } \\
\text { de serviços básicos de saúde }\end{array}$ & 1 & 0 & 1 \\
\hline $\begin{array}{l}\text { 11. Avaliação e agentes comunitários de saúde/Avaliação e } \\
\text { Programa de Saúde da Família }\end{array}$ & 7 & 5 & 2 \\
\hline 12. Avaliação e atenção primária & 25 & 12 & 13 \\
\hline $\begin{array}{l}\text { 13. Avaliação e cuidados de saúde primários/avaliação e } \\
\text { cuidados primários/avaliação e cuidados primários de saúde }\end{array}$ & 4 & 0 & 4 \\
\hline $\begin{array}{l}\text { 14. Avaliação e Saúde da Família/Avaliação em Saúde e } \\
\text { Saúde da Família }\end{array}$ & 16 & 7 & 9 \\
\hline $\begin{array}{l}\text { 15. Avaliação da qualidade dos cuidados/da assistência à } \\
\text { saúde e atenção primária }\end{array}$ & 4 & 0 & 4 \\
\hline Total & 181 & 116 & 65 \\
\hline
\end{tabular}

Fonte: Elaboração própria.

anos da presença ou não de cada termo e com isso podermos inferir uma aproximação objetiva para a história da publicação dos artigos na Revista no contexto de mudanças que a atenção primária à saúde vem passando no Brasil, desde a criação do então PACS e PSF na década de 1990, o papel da Associação Brasileira de Saúde Coletiva (Abrasco), a transformação do PSF em "Estratégia de Saúde da Família”, a Política Nacional de Atenção Básica (PNAB, 1a edição em 2006). Por isso, escolhemos os termos "ABRASCO", "PSF", "atenção básica", "ESF (Equipe de Saúde da Família)”, "ESF (Estratégia de Saúde da Família)", "PNAB", "APS” para uma busca específica no corpo de cada texto publicado. Curiosamente os artigos publicados no período em questão utilizaram a mesma abreviatura "ESF" ou "eSF" tanto para designar "Equipe de Saúde da Família” (forma de organizar um grupo de profissionais em unidades de saúde, como postos de saúde, centros de saúde ou unidades de saúde familiar) como "Estratégia de Saúde da Família" (enquanto modelo estruturante de atenção à saúde). A análise traz a evolução da presença de cada um dos termos pré-selecionados, com participação incipiente de artigos que mencionam a "ABRASCO" como uma das referências nos temas de "avaliação" e "atenção básica/atenção primária". Já os termos "PSF” e "ESF (Estratégia de Saúde da Família) são aqueles que ao longo do tempo obtiveram um maior número de citações com valor máximo no período 2010-2014, quando então decrescem e são ultrapassados pelo termo "APS" entre 2019-2020. Com a criação da SAPS/MS em maio/2019 12 e com o novo modelo de financiamento federal para a atenção primária à Saúde 


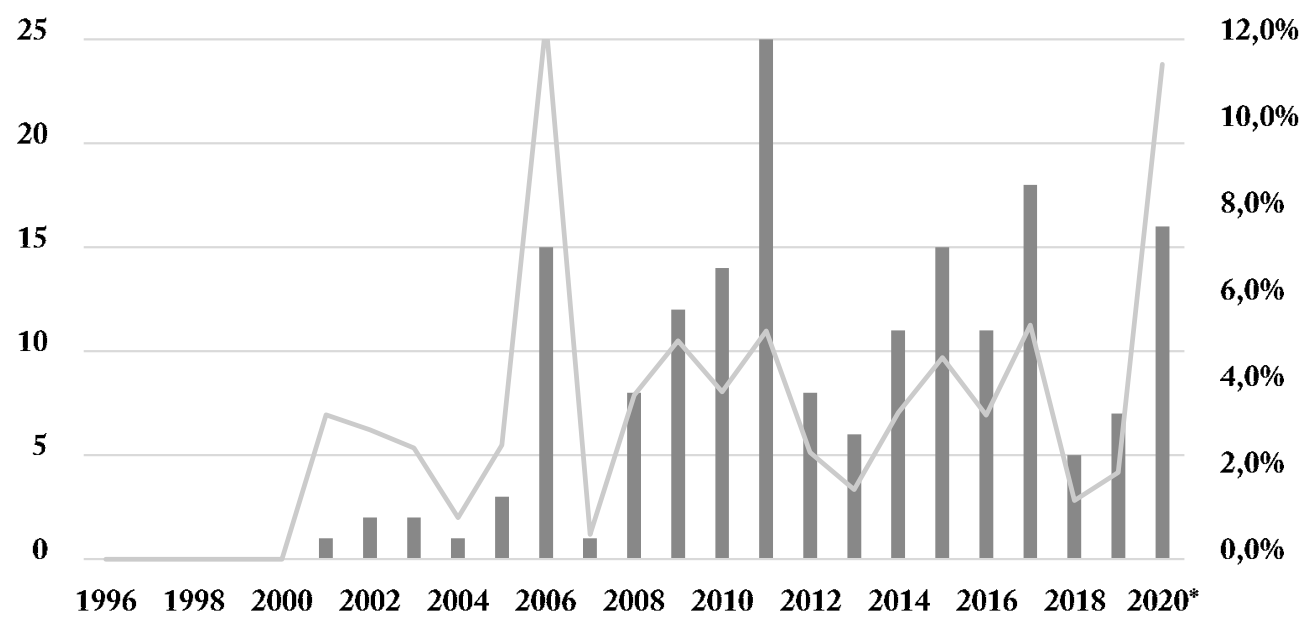

Amostra selecionada $(\mathbf{n}=\mathbf{1 8 1})$ (\%) em relação ao total de artigos publicados

Gráfico 1. Distribuição dos artigos pré-selecionados e proporção de artigos em relação ao total publicado. Revista Ciência \& Saúde Coletiva, 1996-2020 ( $\mathrm{n}=181)$.

${ }^{*}$ Dados de 2020, até o mês de abril.

Fonte: Elaboração própria, a partir dos dados coletados sobre o número total de artigos em https://analytics.scielo.org/w/ publication/article_by_publication_year e totalizando o total de artigos selecionados dentro dos critérios estipulados pelos autores.

- o "Previne Brasil"13 -, espera-se que esse o uso do termo "atenção primária", "atenção primária à saúde", passe a se consolidar e venha a obter um maior número de citações a partir de 2020 (Gráfico 2). Destacamos que em 2020, o Gráfico 2 registra no período “2019-2020” apenas os artigos publicados até o mês de abril/2020 (ou seja, 16 meses), um período bem inferior aos demais utilizados para sua elaboração (48 meses).

\section{Resultados da 2a etapa: o perfil da amostra de artigos selecionados para leitura na íntegra $(\mathrm{N}=65)$}

Um subconjunto de 65 artigos foi lido na íntegra e classificado na base de dados criada segundo as variáveis: filiação institucional do $1^{\circ}$ autor do artigo, classificação temática predominante, local do estudo, objeto/unidade de análise, tipo de amostra/censo, período de coleta de dados e fonte/material utilizado (Quadro 1).

Do total de artigo selecionados, $87,9 \%$ são artigos cujos primeiros autores possuem filiações institucionais brasileiras. Destacam-se os estados do Rio de Janeiro, São Paulo, Minas Gerais e Rio
Grande do Sul, que juntos possuem 53,0\% do total dos textos levantados. Observamos ainda que todas as regiões estão representadas, ainda que a Região Norte, registre timidamente apenas 3,0\% de autores nos estados do Amazonas e Tocantins. Entre os países estrangeiros, Portugal destaca-se com 9,1\% de autores, sendo este valor superior a 11 estados brasileiros individualmente (Pernambuco, Rio Grande do Norte, Bahia, Maranhão, Paraná, Distrito Federal, Santa Catarina, Ceará, Paraíba, Tocantins e Amazonas). Percebe-se, com isso, o grande potencial que a Revista consolidou em Portugal na área de avaliação e cuidados de saúde primários.

\section{Classificação temática predominante}

A leitura na íntegra dos 65 artigos selecionados na amostra bibliográfica, permitiu-nos aproximar os temas principais, classificando os textos pela sua abordagem predominante na área de avaliação (Tabela 2). Do total de artigos, ao se estratificar em dois grupos, chama-nos a atenção as diferenças registradas ao longo dos últimos 25 anos na Revista Ciência \& Saúde Coletiva. 
Quadro 1. Revisão da literatura realizada segundo classificação temática predominante e variáveis selecionadas. Revista Ciência \& Saúde Coletiva, 1996-2020 (n=65).

\begin{tabular}{|c|c|c|c|c|c|}
\hline $\mathbf{n}$ & Autores (ano) & Local do estudo & $\begin{array}{l}\text { Objeto/unidade de } \\
\text { análise }\end{array}$ & Amostra/censo & $\begin{array}{l}\text { Período } \\
\text { de coleta } \\
\text { de dados }\end{array}$ \\
\hline \multicolumn{6}{|c|}{ 01. Avaliação normativa (diversas referências) } \\
\hline 1 & $\begin{array}{l}\text { Tomasi et al. } \\
(2011)\end{array}$ & $\begin{array}{l}\text { Alguns estados da Região } \\
\text { Nordeste e Sul do Brasil }\end{array}$ & $\begin{array}{l}\text { Atendimentos realizados } \\
\text { em unidades de saúde }\end{array}$ & $\begin{array}{l}\mathrm{n}=26.019 \\
\text { atendimentos }\end{array}$ & 2008 \\
\hline 2 & $\begin{array}{l}\text { Cardoso et al. } \\
(2015)\end{array}$ & $\begin{array}{l}\text { Municípios do nordeste de } \\
\text { Minas Gerais }\end{array}$ & Municípios & $\begin{array}{l}\mathrm{n}=63 \\
\text { municípios }\end{array}$ & 2011 \\
\hline 3 & Neto et al. (2016) & $\begin{array}{l}\text { Curitiba (Paraná), Rio de } \\
\text { Janeiro (Rio de Janeiro), Lisboa } \\
\text { (Portugal) }\end{array}$ & Municípios & $\begin{array}{l}\mathrm{n}=3(\text { série de } \\
\text { casos) }\end{array}$ & 2015 \\
\hline 4 & $\begin{array}{l}\text { Salazar et al. } \\
(2017)\end{array}$ & $\begin{array}{l}\text { Município do Rio de Janeiro, } \\
\text { e Brasil }\end{array}$ & $\begin{array}{l}\text { Equipes de saúde da } \\
\text { família }\end{array}$ & $\begin{array}{l}\mathrm{n} 1=324(\text { Rio }) \\
\text { equipes; } \mathrm{n} 2= \\
17.200 \text { (Brasil) }\end{array}$ & 2012 \\
\hline 5 & $\begin{array}{l}\text { Monteiro et al. } \\
(2017)\end{array}$ & $\begin{array}{l}\text { ACeS Amadora, ACeS Almada- } \\
\text { Seixal (ARSLVT, Portugal) }\end{array}$ & Homens e mulheres & $\begin{array}{l}\mathrm{n}=176.293 \\
\text { pessoas }\end{array}$ & 2016 \\
\hline 6 & $\begin{array}{l}\text { Monteiro et al. } \\
(2017)\end{array}$ & $\begin{array}{l}\text { ACeS Oeste Norte } x \\
\text { Administração Regional } \\
\text { de Lisboa e Vale do Tejo } \\
\text { (ARSLVT), Portugal }\end{array}$ & Homens e mulheres & $\begin{array}{l}\mathrm{n}=176.293 \\
\text { pessoas }\end{array}$ & 2016 \\
\hline 7 & $\begin{array}{l}\text { Soranz et al. } \\
(2017)\end{array}$ & $\begin{array}{l}\text { Município do Rio de Janeiro, } \\
\text { Rio de Janeiro }\end{array}$ & Homens e mulheres & $\begin{array}{l}\mathrm{n} \sim 3 \text { milhões } \\
\text { de pessoas }\end{array}$ & 2016 \\
\hline 8 & $\begin{array}{l}\text { Santos e Hugo } \\
(2018)\end{array}$ & Brasil & \begin{tabular}{|l|} 
Equipes de Saúde Bucal \\
na Estratégia de Saúde da \\
Família
\end{tabular} & $\begin{array}{l}\mathrm{n}=18.114 \\
\text { equipes de } \\
\text { Saúde Bucal }\end{array}$ & $\begin{array}{c}2013- \\
2014\end{array}$ \\
\hline 9 & Monteiro (2020) & Portugal & Homens e mulheres & $\begin{array}{l}\mathrm{n}=10.220 .858 \\
\text { pessoas }\end{array}$ & 2019 \\
\hline 10 & \begin{tabular}{|l} 
Pinto e Santos \\
$(2020)$
\end{tabular} & $\begin{array}{l}\text { Área de Planejamento do } \\
\text { município do Rio de Janeiro }\end{array}$ & $\begin{array}{l}\text { Adultos com } 18 \text { anos ou } \\
\text { mais }\end{array}$ & $\begin{array}{l}\mathrm{n}=115.280 \\
\text { pessoas }\end{array}$ & $\begin{array}{c}2014 \mathrm{a} \\
2015\end{array}$ \\
\hline \multicolumn{6}{|c|}{ 02. Análise político-institucional } \\
\hline 11 & $\begin{array}{l}\text { Biscaia e Heleno } \\
(2017)\end{array}$ & $\begin{array}{l}\text { Unidade de Saúde da Família da } \\
\text { Marginal, Cascais, Portugal }\end{array}$ & $\begin{array}{l}\text { Unidade de saúde da } \\
\text { família }\end{array}$ & Estudo de caso & 2016 \\
\hline 12 & Reis et al. (2019) & Brasil & $\begin{array}{l}\text { Criação da Secretaria } \\
\text { de Atenção Primária à } \\
\text { Saúde no Ministério da } \\
\text { Saúde }\end{array}$ & Estudo de caso & 2019 \\
\hline \multicolumn{6}{|c|}{ 03. Análise exploratória qualitativa (Minayo, 2003) } \\
\hline 13 & $\begin{array}{l}\text { Nascimento e } \\
\text { Nascimento } \\
(2005)\end{array}$ & Município de Jequié, Bahia & Enfermeiras & $\begin{array}{l}\mathrm{n}=14 \\
\text { enfermeiras }\end{array}$ & $\begin{array}{c}1999 \mathrm{a} \\
2002\end{array}$ \\
\hline 14 & $\begin{array}{l}\text { Galavote et al. } \\
(2011)\end{array}$ & $\begin{array}{l}\text { Município de Vitória, Espírito } \\
\text { Santo }\end{array}$ & $\begin{array}{l}\text { Agentes comunitários de } \\
\text { saúde }\end{array}$ & $\begin{array}{l}\mathrm{n}=14 \text { agentes } \\
\text { comunitários } \\
\text { de saúde }\end{array}$ & $\begin{array}{c}2005 \mathrm{a} \\
2006\end{array}$ \\
\hline 15 & $\begin{array}{l}\text { Pinheiro et al. } \\
(2012)\end{array}$ & $\begin{array}{l}\text { Município de Florianópolis, } \\
\text { Santa Catarina }\end{array}$ & Enfermeiras & $\begin{array}{l}\mathrm{n}=14 \\
\text { enfermeiras }\end{array}$ & 2010 \\
\hline 16 & $\begin{array}{l}\text { Engstrom et al. } \\
(2020)\end{array}$ & $\begin{array}{l}\text { Município do Rio de Janeiro, } \\
\text { Rio de Janeiro }\end{array}$ & Alunos & $\begin{array}{l}\mathrm{n}=42 \text { alunos } \\
\text { egressos }\end{array}$ & 2016 \\
\hline \multicolumn{6}{|c|}{ 04. Teoria da avaliação e implantação de programas (Hartz, 1997; Contandriopoulos et al, 1997) } \\
\hline 17 & Bodstein (2002) & Brasil & $\begin{array}{l}\text { Processo de } \\
\text { descentralização do SUS } \\
\text { e a atenção básica }\end{array}$ & estudo de caso & 2001 \\
\hline 18 & $\begin{array}{l}\text { Albuquerque et } \\
\text { al. (2007) }\end{array}$ & $\begin{array}{l}\text { Município de Recife, } \\
\text { Pernambuco }\end{array}$ & \begin{tabular}{|l|} 
Unidades básicas de \\
saúde (n1) e unidades de \\
saúde da família (n2)
\end{tabular} & $\mathrm{n} 1=42 ; \mathrm{n} 2=84$ & 2002 \\
\hline
\end{tabular}


Quadro 1. Revisão da literatura realizada segundo classificação temática predominante e variáveis selecionadas. Revista Ciência \& Saúde Coletiva, 1996-2020 ( $\mathrm{n}=65)$.

\begin{tabular}{|c|c|c|c|c|c|}
\hline $\mathbf{n}$ & Autores (ano) & Local do estudo & $\begin{array}{l}\text { Objeto/unidade de } \\
\text { análise }\end{array}$ & Amostra/censo & $\begin{array}{l}\text { Período } \\
\text { de coleta } \\
\text { de dados }\end{array}$ \\
\hline 19 & $\begin{array}{l}\text { Rocha e Sá } \\
(2011)\end{array}$ & Portugal & $\begin{array}{l}\text { Unidades de saúde da } \\
\text { família (USF) }\end{array}$ & $\begin{array}{l}\mathrm{n}=11 \text { USF } \\
\text { (série de casos) }\end{array}$ & 2009 \\
\hline \multicolumn{6}{|c|}{ 05. Triângulo de Governo de Matus (Matus, 1972) } \\
\hline 20 & $\begin{array}{l}\text { Sampaio et al. } \\
\text { (2011) }\end{array}$ & $\begin{array}{l}\text { Secretaria Estadual de Saúde de } \\
\text { um estado do Nordeste }\end{array}$ & $\begin{array}{l}\text { Secretaria Estadual de } \\
\text { Saúde }\end{array}$ & estudo de caso & 2006 \\
\hline \multicolumn{6}{|c|}{ 06. Teoria da Avaliação de Impacto em Políticas Públicas (Draibe, 2004) } \\
\hline 21 & $\begin{array}{l}\text { Roncalli e Lima } \\
(2008)\end{array}$ & $\begin{array}{l}\text { Alguns municípios da Região } \\
\text { Nordeste com população maior } \\
\text { que } 100 \text { mil habitantes }\end{array}$ & $\begin{array}{l}\text { Crianças menores de } \\
\text { cinco anos }\end{array}$ & $\begin{array}{l}\mathrm{n}=2.144 \\
\text { crianças }\end{array}$ & 2005 \\
\hline \multicolumn{6}{|c|}{ 07. Teoria da complexidade dos sistemas de saúde: as quatro lógicas existentes } \\
\hline 22 & $\begin{array}{l}\text { Contandriopoulos } \\
(2006)\end{array}$ & Brasil & $\begin{array}{l}\text { Pesquisa avaliativa, } \\
\text { avaliação normativa, } \\
\text { tomada de decisão }\end{array}$ & Estudo de caso & 2006 \\
\hline \multicolumn{6}{|c|}{ 08. Teoria da Avaliação e uso de modelo lógico (Hartz, 1997) } \\
\hline 23 & Felisberto (2006) & Brasil & $\begin{array}{l}\text { Institucionalização da } \\
\text { avaliação em saúde e } \\
\text { atenção básica }\end{array}$ & Estudo de caso & 2006 \\
\hline 24 & $\begin{array}{l}\text { Costa et al. } \\
(2011)\end{array}$ & $\begin{array}{l}\text { Município de Recife, } \\
\text { Pernambuco }\end{array}$ & $\begin{array}{l}\text { Equipes de saúde da } \\
\text { família }\end{array}$ & $\mathrm{n}=72$ & 2010 \\
\hline \multicolumn{6}{|c|}{ 09. Avaliação descritiva da situação local de situação (Testa, 1992) } \\
\hline 25 & $\begin{array}{l}\text { Gomes et al. } \\
(2009)\end{array}$ & $\begin{array}{l}\text { Município de Paula Cândido, } \\
\text { Minas Gerais }\end{array}$ & $\begin{array}{l}\text { Famílias não cobertas } \\
\text { pelas ESF (1992) e } \\
\text { cobertas pelas ESF (2003) }\end{array}$ & $\begin{array}{l}\mathrm{n} 1=\mathrm{n} 2=127 \\
\text { famílias }\end{array}$ & $\begin{array}{c}1992 / \\
2003\end{array}$ \\
\hline \multicolumn{6}{|c|}{ 10. Teoria da avaliação de estrutura/processo/resultado (Donabedian, 1990) } \\
\hline 26 & $\begin{array}{l}\text { Costa e Pinto } \\
(2002)\end{array}$ & Todos os municípios do Brasil & $\begin{array}{l}\text { Municípios por porte } \\
\text { populacional }\end{array}$ & $\begin{array}{l}\mathrm{n}=5.354 \\
\text { municípios }\end{array}$ & 2002 \\
\hline 27 & $\begin{array}{l}\text { Machado et al. } \\
(2004)\end{array}$ & $\begin{array}{l}\text { Municípios e regiões de saúde } \\
\text { de Minas Gerais }\end{array}$ & $\begin{array}{l}\text { Municípios e regiões de } \\
\text { Minas Gerais }\end{array}$ & $\begin{array}{l}\mathrm{n} \sim 800 \\
\text { municípios } \\
\end{array}$ & 2003 \\
\hline 28 & $\begin{array}{l}\text { Facchini et al. } \\
(2006)\end{array}$ & $\begin{array}{l}\text { Municípios de Alagoas, Paraíba, } \\
\text { Pernambuco, Piauí, Rio Grande } \\
\text { do Norte, Rio Grande do Sul, } \\
\text { Santa Catarina }\end{array}$ & $\begin{array}{l}\text { Conselheiros municipais } \\
\text { de saúde (n1), secretários } \\
\text { municipais de saúde } \\
\text { (n2), coordenadores de } \\
\text { atenção básica }(\mathrm{n} 3) \\
\end{array}$ & $\begin{array}{l}\mathrm{n} 1=41, \mathrm{n} 2= \\
29, \mathrm{n} 3=32\end{array}$ & 2005 \\
\hline 29 & $\begin{array}{l}\text { Pereira et al. } \\
(2006)\end{array}$ & $\begin{array}{l}\text { Municípios do Amapá, } \\
\text { Maranhão, Pará e Tocantins }\end{array}$ & $\begin{array}{l}\text { Municípios com mais de } \\
100 \text { mil habitantes }\end{array}$ & $\begin{array}{l}\mathrm{n}=16 \\
\text { municípios }\end{array}$ & 2006 \\
\hline 30 & $\begin{array}{l}\text { Caldeira et al. } \\
(2010)\end{array}$ & $\begin{array}{l}\text { Município de Montes Claros, } \\
\text { Minas Gerais }\end{array}$ & $\begin{array}{l}\text { Crianças menores de dois } \\
\text { anos }\end{array}$ & $\begin{array}{l}\mathrm{n}=1.200 \\
\text { famílias, } 595 \\
\text { mães }\end{array}$ & 2006 \\
\hline 31 & $\begin{array}{l}\text { Costa et al. } \\
(2011)\end{array}$ & $\begin{array}{l}\text { Município de Teixeiras, Minas } \\
\text { Gerais }\end{array}$ & $\begin{array}{l}\text { Crianças menores de dois } \\
\text { anos }\end{array}$ & $\mathrm{n}=161$ mães & 2006 \\
\hline 32 & $\begin{array}{l}\text { Serapioni e Silva } \\
(2011)\end{array}$ & Regiões do estado do Ceará & $\begin{array}{l}\text { Equipes de saúde da } \\
\text { família, profissionais } \\
\text { de saúde, gestores, } \\
\text { conselheiros de saúde, } \\
\text { acadêmicos, usuários }\end{array}$ & $\begin{array}{l}\text { Estudo de } \\
\text { caso }+\mathrm{n} 1=340 \\
\text { usuários }\end{array}$ & 2010 \\
\hline 33 & $\begin{array}{l}\text { Portela e Ribeiro } \\
(2011)\end{array}$ & $\begin{array}{l}\text { Municípios brasileiros com } \\
\text { mais de } 100 \text { mil habitantes }\end{array}$ & Municípios & $\begin{array}{l}\mathrm{n}=185 \\
\text { municípios }\end{array}$ & 2007 \\
\hline 34 & $\begin{array}{l}\text { Mendes et al. } \\
(2012)\end{array}$ & $\begin{array}{l}\text { Município de Recife, } \\
\text { Pernambuco }\end{array}$ & $\begin{array}{l}\text { Usuários (n1), médicos } \\
\text { (n2), enfermeiros (n3) }\end{array}$ & $\begin{array}{l}\mathrm{n} 1=1.180, \mathrm{n} 2 \\
=61, \mathrm{n} 3=56\end{array}$ & 2009 \\
\hline
\end{tabular}


Quadro 1. Revisão da literatura realizada segundo classificação temática predominante e variáveis selecionadas. Revista Ciência \& Saúde Coletiva, 1996-2020 ( $\mathrm{n}=65)$.

\begin{tabular}{|c|c|c|c|c|c|}
\hline $\mathbf{n}$ & Autores (ano) & Local do estudo & $\begin{array}{l}\text { Objeto/unidade de } \\
\text { análise }\end{array}$ & Amostra/censo & $\begin{array}{l}\text { Período } \\
\text { de coleta } \\
\text { de dados }\end{array}$ \\
\hline 35 & $\begin{array}{l}\text { Bulgareli et al. } \\
(2014)\end{array}$ & $\begin{array}{l}\text { Município de Marília, São } \\
\text { Paulo }\end{array}$ & $\begin{array}{l}\text { Unidades básicas de } \\
\text { saúde (n1) e unidades de } \\
\text { saúde da família (n2) }\end{array}$ & $\begin{array}{l}\mathrm{n} 1=6 \mathrm{UBS}, \mathrm{n} 2 \\
=11 \text { USF }\end{array}$ & $\begin{array}{c}2007- \\
2009\end{array}$ \\
\hline \multicolumn{6}{|c|}{ 11. Teoria da Gestão Clínica em Atenção Primária à Saúde (Wagner, 2012) } \\
\hline 36 & $\begin{array}{l}\text { Janett e Yeracaris } \\
(2020)\end{array}$ & Estados Unidos & $\begin{array}{l}\text { Uso do prontuário } \\
\text { eletrônico na atenção } \\
\text { primária à saúde }\end{array}$ & Estudo de caso & 2019 \\
\hline \multicolumn{6}{|c|}{ 12. Teoria sobre acesso e utilização dos serviços de saúde (Andersen, 1995) } \\
\hline 37 & $\begin{array}{l}\text { Bousquat et al. } \\
(2012)\end{array}$ & $\begin{array}{l}\text { Município de Santo André, São } \\
\text { Paulo }\end{array}$ & Homens e mulheres & $\mathrm{n}=175$ pessoas & 2011 \\
\hline \multicolumn{6}{|c|}{$\begin{array}{l}\text { 13. Teoria Epidemiológica, estudos agregados - ecológicos e estudos de base populacional. (Medronho et al, } \\
\text { 2009) }\end{array}$} \\
\hline 38 & $\begin{array}{l}\text { d'Ávila Viana et } \\
\text { al. (2006) }\end{array}$ & $\begin{array}{l}\text { Todos os municípios do Estado } \\
\text { de São Paulo }\end{array}$ & Municípios & $\begin{array}{l}\mathrm{n}=62 \\
\text { municípios }\end{array}$ & 2005 \\
\hline 39 & $\begin{array}{l}\text { Szwarcwald et al. } \\
(2006)\end{array}$ & $\begin{array}{l}\text { Alguns municípios do estado } \\
\text { do Rio de Janeiro, com } \\
\text { população maior que } 100 \text { mil } \\
\text { habitantes }\end{array}$ & $\begin{array}{l}\text { Adultos com } 18 \text { anos ou } \\
\text { mais e mães de crianças } \\
\text { menores de } 2 \text { anos }\end{array}$ & $\begin{array}{l}\mathrm{n}=1.970 \\
\text { pessoas }\end{array}$ & 2005 \\
\hline 40 & $\begin{array}{l}\text { Ribeiro et al. } \\
(2010)\end{array}$ & $\begin{array}{l}\text { Município de Teresópolis, Rio } \\
\text { de Janeiro }\end{array}$ & $\begin{array}{l}\text { Crianças menores de } \\
\text { cinco anos }\end{array}$ & $\begin{array}{l}\mathrm{n}=594 \\
\text { responsáveis } \\
\text { pelas crianças }\end{array}$ & 2005 \\
\hline 41 & $\begin{array}{l}\text { Busato et al. } \\
(2011)\end{array}$ & Município de Curitiba, Paraná & Cirurgiões-dentista & $\begin{array}{l}\mathrm{n}=191 \\
\text { dentistas }\end{array}$ & 2006 \\
\hline \multicolumn{6}{|c|}{ 14. Teoria dos atributos da Atenção Primária à Saúde (APS) (Starfield, 2002) } \\
\hline 42 & Elias et al. (2006) & $\begin{array}{l}\text { Todos os municípios do Estado } \\
\text { de São Paulo }\end{array}$ & $\begin{array}{l}\text { Usuários }(\mathrm{n} 1) \text { e } \\
\text { profissionais de saúde } \\
(\mathrm{n} 2), \text { e gestores }(\mathrm{n} 3)\end{array}$ & $\begin{array}{l}\mathrm{n} 1=1.117, \mathrm{n} 2 \\
=600(?), \mathrm{n} 3= \\
343(?)\end{array}$ & 2005 \\
\hline 43 & $\begin{array}{l}\text { Ibañez et al. } \\
(2006)\end{array}$ & $\begin{array}{l}\text { Municípios de São Paulo com } \\
\text { população maior que } 100 \text { mil } \\
\text { habitantes }\end{array}$ & $\begin{array}{l}\text { Usuários }(\mathrm{n} 1) \text { e } \\
\text { profissionais de saúde } \\
(\mathrm{n} 2)\end{array}$ & $\begin{array}{l}\mathrm{n} 1=2.923 ; \mathrm{n} 2 \\
=167 \text { prof. de } \\
\text { saúde }\end{array}$ & 2005 \\
\hline 44 & $\begin{array}{l}\text { Alves Leão \& } \\
\text { Caldeira (2011) } \\
\end{array}$ & $\begin{array}{l}\text { Município de Montes Claros, } \\
\text { Minas Gerais }\end{array}$ & $\begin{array}{l}\text { Crianças menores de dois } \\
\text { anos }\end{array}$ & $\mathrm{n}=350$ mães & 2009 \\
\hline 45 & Reis et al. (2013) & $\begin{array}{l}\text { Município de São Luís, } \\
\text { Maranhão }\end{array}$ & $\begin{array}{l}\text { Usuários (n1) e } \\
\text { profissionais de saúde } \\
(\mathrm{n} 2) \text {, e gestores (n3) }\end{array}$ & $\begin{array}{l}\mathrm{n} 1=882, \mathrm{n} 2= \\
80, \mathrm{n} 3=30\end{array}$ & $\begin{array}{c}2010- \\
2011\end{array}$ \\
\hline 46 & $\begin{array}{l}\text { Alencar et al. } \\
(2014)\end{array}$ & $\begin{array}{l}\text { Município de São Luís, } \\
\text { Maranhão }\end{array}$ & $\begin{array}{l}\text { Usuários }(\mathrm{n} 1) \text { e } \\
\text { profissionais de saúde } \\
(\mathrm{n} 2), \text { e gestores }(\mathrm{n} 3)\end{array}$ & $\begin{array}{l}\mathrm{n} 1=883, \mathrm{n} 2= \\
80, \mathrm{n} 3=32\end{array}$ & $\begin{array}{c}2010- \\
2011\end{array}$ \\
\hline 47 & $\begin{array}{l}\text { Marques et al } \\
(2014) \text {. }\end{array}$ & $\begin{array}{l}\text { Município de São Francisco, } \\
\text { Minas Gerais }\end{array}$ & $\begin{array}{l}\text { Crianças menores } \\
\text { de cinco anos em } \\
\text { comunidade quilombola } \\
\end{array}$ & $\mathrm{n}=76$ famílias & 2011 \\
\hline 48 & $\begin{array}{l}\text { Araújo et al. } \\
(2014)\end{array}$ & $\begin{array}{l}\text { Município de Macaíba, Rio } \\
\text { Grande do Norte }\end{array}$ & Idosos & $\mathrm{n}=100$ & 2012 \\
\hline 49 & $\begin{array}{l}\text { Mesquita Filho et } \\
\text { al. (2014) }\end{array}$ & $\begin{array}{l}\text { Município de Pouso Alegre, } \\
\text { Minas Gerais }\end{array}$ & $\begin{array}{l}\text { Crianças menores de dois } \\
\text { anos }\end{array}$ & $\begin{array}{l}\mathrm{n}=419 \\
\text { cuidadores de } \\
\text { crianças }\end{array}$ & 2009 \\
\hline 50 & $\begin{array}{l}\text { Quaresma e Stein } \\
(2015)\end{array}$ & Município de Palmas. Tocantins & $\begin{array}{l}\text { Crianças e adolescentes } \\
\text { entre } 12 \text { e } 18 \text { anos }\end{array}$ & $\begin{array}{l}\mathrm{n}=469 \\
\text { crianças e } \\
\text { adolescentes }\end{array}$ & 2013 \\
\hline
\end{tabular}


Quadro 1. Revisão da literatura realizada segundo classificação temática predominante e variáveis selecionadas. Revista Ciência \& Saúde Coletiva, 1996-2020 ( $\mathrm{n}=65)$.

\begin{tabular}{|c|c|c|c|c|c|}
\hline $\mathbf{n}$ & Autores (ano) & Local do estudo & $\begin{array}{l}\text { Objeto/unidade de } \\
\text { análise }\end{array}$ & Amostra/censo & $\begin{array}{l}\text { Período } \\
\text { de coleta } \\
\text { de dados }\end{array}$ \\
\hline 51 & $\begin{array}{l}\text { Harzheim et al. } \\
(2016)\end{array}$ & $\begin{array}{l}\text { Município do Rio de Janeiro, } \\
\text { Rio de Janeiro }\end{array}$ & $\begin{array}{l}\text { Adultos } \geq 18 \text { anos, e } \\
\text { responsáveis de crianças } \\
<12 \text { anos }\end{array}$ & $\begin{array}{l}\mathrm{n} 1=3.530 \text { e } \mathrm{n} 2 \\
=3.145\end{array}$ & 2014 \\
\hline 52 & $\begin{array}{l}\text { Pinto et al. } \\
(2017)\end{array}$ & $\begin{array}{l}\text { Bairro da Rocinha, município } \\
\text { do Rio de Janeiro, Rio de } \\
\text { Janeiro }\end{array}$ & $\begin{array}{l}\text { Adultos } \geq 18 \text { anos, e } \\
\text { responsáveis de crianças } \\
<12 \text { anos }\end{array}$ & $\begin{array}{l}\mathrm{n} 1=433 \text { e } \mathrm{n} 2 \\
=369\end{array}$ & 2014 \\
\hline 53 & $\begin{array}{l}\text { Sellera et al. } \\
(2020)\end{array}$ & Brasil & $\begin{array}{l}\text { Institucionalização da } \\
\text { avaliação em saúde e } \\
\text { atenção básica }\end{array}$ & Estudo de caso & 2019 \\
\hline \multicolumn{6}{|c|}{ 15. Teoria de Billings (1990), sobre Ambulatory Care Sensitive Conditions (ACSC) } \\
\hline 54 & $\begin{array}{l}\text { Rehem e Egry } \\
(2011)\end{array}$ & $\begin{array}{l}\text { Municípios do Estado de São } \\
\text { Paulo }\end{array}$ & Homens e mulheres & $\begin{array}{l}\mathrm{n} \sim 400 \text { mil } \\
\text { internações/ano }\end{array}$ & $\begin{array}{c}2000 \mathrm{a} \\
2007\end{array}$ \\
\hline 55 & $\begin{array}{l}\text { Pitilin et al. } \\
(2015)\end{array}$ & $\begin{array}{l}\text { Municípios de Guarapuava, } \\
\text { Paraná }\end{array}$ & Mulheres & $\begin{array}{l}\mathrm{n}=429 \\
\text { internações }\end{array}$ & 2013 \\
\hline 56 & $\begin{array}{l}\text { Avelino et al. } \\
(2015)\end{array}$ & $\begin{array}{l}\text { Município de Alfenas, Minas } \\
\text { Gerais }\end{array}$ & Homens e mulheres & $\begin{array}{l}\mathrm{n}=2.200 \\
\text { internações }\end{array}$ & $\begin{array}{c}2008 \text { a } \\
2012 \\
\end{array}$ \\
\hline 57 & $\begin{array}{l}\text { Costa et al. } \\
(2016)\end{array}$ & $\begin{array}{l}\text { Município de Porto Alegre, Rio } \\
\text { Grande do Sul }\end{array}$ & Homens e mulheres & $\begin{array}{l}\text { total de } \\
\text { internações não } \\
\text { especificado }\end{array}$ & $\begin{array}{l}1998 \mathrm{a} \\
2012\end{array}$ \\
\hline 58 & $\begin{array}{l}\text { Gonçalves et al. } \\
(2016)\end{array}$ & Municípios do Nordeste & Homens e mulheres & $\begin{array}{l}\mathrm{n}=181.152 \\
\text { internações }\end{array}$ & $\begin{array}{c}2012 \mathrm{a} \\
2015 \\
\end{array}$ \\
\hline 59 & $\begin{array}{l}\text { Magalhães e } \\
\text { Morais Neto } \\
(2017)\end{array}$ & $\begin{array}{l}\text { Distritos Sanitários do } \\
\text { Município de Goiânia, Goiás. }\end{array}$ & Homens e mulheres & $\begin{array}{l}\mathrm{n}=502.908 \\
\text { internações }\end{array}$ & $\begin{array}{c}2008 \text { a } \\
2013\end{array}$ \\
\hline 60 & $\begin{array}{l}\text { Morimoto e } \\
\text { Costa (2017) }\end{array}$ & $\begin{array}{l}\text { Município de São Leopoldo, } \\
\text { Rio Grande do Sul. }\end{array}$ & Homens e mulheres & $\begin{array}{l}\mathrm{n}=10 \text { mil } \\
\text { internações/ano }\end{array}$ & $\begin{array}{c}2003 a \\
2012 \\
\end{array}$ \\
\hline 61 & $\begin{array}{l}\text { Pinto e } \\
\text { Giovanella (2018) }\end{array}$ & $\begin{array}{l}\text { Brasil (capitais e interiores), } \\
\text { outras capitais selecionadas }\end{array}$ & Homens e mulheres & $\begin{array}{l}\mathrm{n}=187 \\
\text { milhões de } \\
\text { internações }\end{array}$ & $\begin{array}{c}2001 \mathrm{a} \\
2016\end{array}$ \\
\hline 62 & \begin{tabular}{|l|} 
Pinto Junior et al. \\
$(2018)$
\end{tabular} & Bahia & $\begin{array}{l}\text { Crianças menores de } \\
\text { cinco anos }\end{array}$ & $\begin{array}{l}\mathrm{n}=810.831 \\
\text { internações }\end{array}$ & $\begin{array}{c}2000 \mathrm{a} \\
2012 \\
\end{array}$ \\
\hline 63 & $\begin{array}{l}\text { Pinto et al. } \\
(2019)\end{array}$ & $\begin{array}{l}\text { Brasil, Brasília, São Paulo, Rio } \\
\text { de Janeiro, Belo Horizonte, } \\
\text { Porto Alegre, Curitiba, } \\
\text { Florianópolis. }\end{array}$ & Homens e mulheres & $\begin{array}{l}\mathrm{n} \sim 20 \text { milhões } \\
\text { de internações }\end{array}$ & $\begin{array}{c}2009 a \\
2018\end{array}$ \\
\hline 64 & Lôbo et al. (2019) & $\begin{array}{l}\text { Municípios do Estado de São } \\
\text { Paulo }\end{array}$ & $\begin{array}{l}\text { Crianças menores de um } \\
\text { ano. }\end{array}$ & $\begin{array}{l}\mathrm{n}=851.713 \\
\text { internações }\end{array}$ & $\begin{array}{c}2008 \text { a } \\
2014 \\
\end{array}$ \\
\hline 65 & $\begin{array}{l}\text { Rocha et al. } \\
(2020)\end{array}$ & Brasil e Portugal & Homens e mulheres & $\begin{array}{l}\mathrm{n} 1=11,6 \\
\text { milhões (Brasil); } \\
\mathrm{n} 2=1 \text { milhão } \\
\text { (Portugal) }\end{array}$ & 2019 \\
\hline
\end{tabular}

Fonte: Elaboração dos autores, a partir da leitura íntegra dos artigos. 


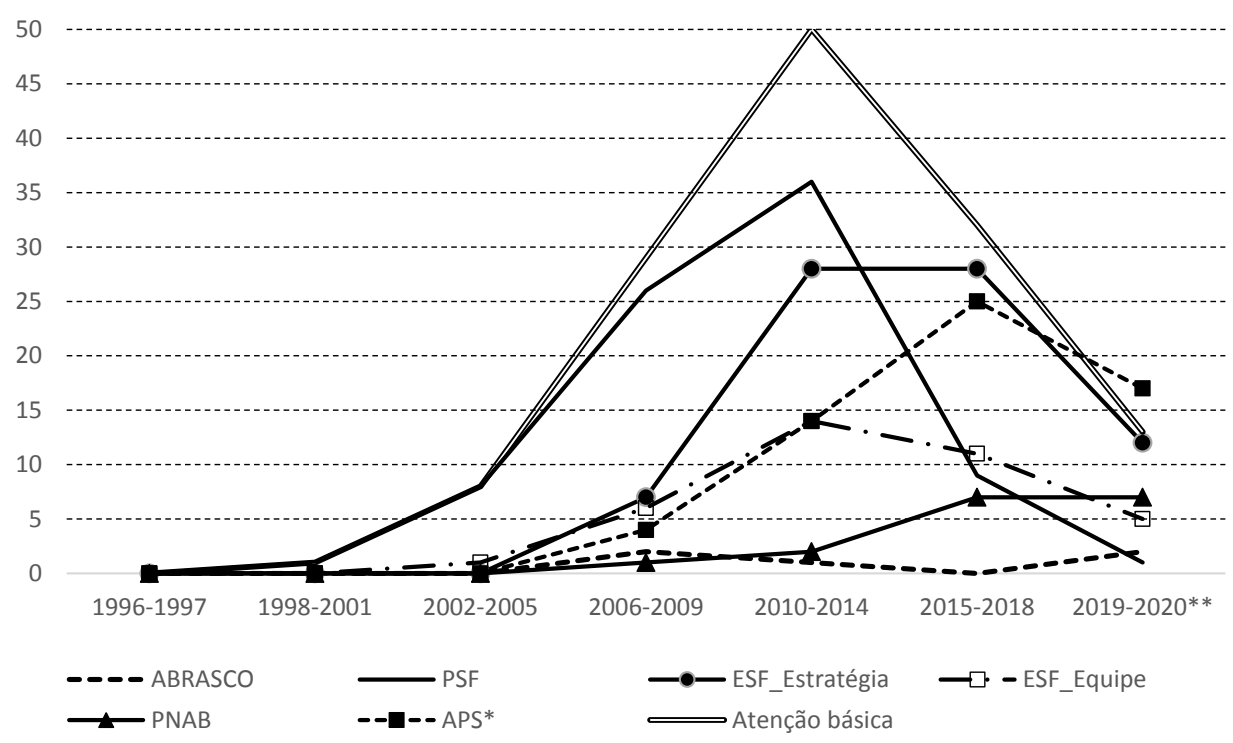

Gráfico 2. Distribuição dos artigos pesquisados sem duplicados segundo palavras-chave específicas selecionadas. Revista Ciência \& Saúde Coletiva, 1996-2020 ( $\mathrm{n}=181)$.

*A palavra-chave "APS" foi encontrada considerando também as palavras associadas "cuidados de saúde primários" e "primary health care". ${ }^{*}$ Dados de 2020 , até o mês de abril.

Fonte: Elaboração própria.

Tabela 2. Revisão bibliográficas sobre avaliação e atenção primária à saúde segundo classificação temática predominante. Revista Ciência \& Saúde Coletiva, 1996-2020 $(\mathrm{n}=65)$.

\section{Classificação temática predominante}

01. Estudos epidemiológicos (com indicadores clínicos e de gestão, podendo incluir as ICSAP)

02. Pesquisas avaliativas com usuários/profissionais de saúde/gestores (muitas utilizando o instrumento PCATool)

03. Pesquisas avaliativas com comparação de modelos de atenção (ESF x modelo tradicional; saúde bucal)

04. Pesquisa avaliativas sobre ações/programas e/ou procedimentos específicos realizados na APS

05. Discussão conceitual e/ou institucional

06. Pesquisas avaliativas com estudos de caso

07. Avaliação da implantação do PAB, das equipes de Saúde da Família, Saúde Bucal (inclusive avaliação econômica/financeira)

08. Pesquisa exploratória sobre processos de trabalho na APS

Total

Fonte: Elaboração própria.

\begin{tabular}{cccccc}
\multicolumn{2}{c}{ Até 2010 } & \multicolumn{2}{c}{ 2011-2020 } & \multicolumn{2}{c}{ Total } \\
\hline $\begin{array}{c}\mathbf{n}^{\circ} \text { de } \\
\text { artigos }\end{array}$ & $\%$ & $\begin{array}{c}\mathbf{n}^{\circ} \text { de } \\
\text { artigos }\end{array}$ & $\%$ & $\begin{array}{c}\mathbf{n}^{\circ} \text { de } \\
\text { artigos }\end{array}$ & $\%$ \\
\hline 1 & 5,6 & 17 & 36,2 & 18 & 27,7
\end{tabular}

16,7

12

$25,5 \quad 15$

$\begin{array}{rrrrrr}4 & 22,2 & 4 & 8,5 & 8 & 12,3 \\ 3 & 16,7 & 5 & 10,6 & 8 & 12,3 \\ & & & & & \\ 1 & 5,6 & 2 & 4,3 & 3 & 4,6 \\ 0 & 0,0 & 4 & 8,5 & 4 & 6,2 \\ 5 & 27,8 & 1 & 2,1 & 6 & 9,2\end{array}$

\begin{tabular}{rrrrrr}
1 & 5,6 & 2 & 4,3 & 3 & 4,6 \\
18 & 100,0 & 47 & 100,0 & 65 & 100,0 \\
\hline
\end{tabular}


No $1^{\circ}$ grupo de artigos, publicados até 2010 destacam as "pesquisas avaliativas com comparação de modelos de atenção (ESF x modelo tradicional; saúde bucal)" e "avaliação da implantação do PAB, das equipes de Saúde da Família, Saúde Bucal (inclusive avaliação econômica/financeira)" que juntos respondem por cerca de $50 \%$ do total de textos selecionados para análise nesse período. No $2^{\circ}$ grupo, para os manuscritos publicados entre 2011 e 2020, as áreas "estudos epidemiológicos (com indicadores clínicos e de gestão, podendo incluir as ICSAP)", e "pesquisas avaliativas com usuários/ profissionais de saúde/gestores (muitas, utilizando o instrumento Primary Care Assessment Tool - PCAT)", somaram juntas 60,4\% do total de artigos publicados sobre avaliação em saúde e atenção básica/atenção primária, na última década (Tabela 3 ).

De forma semelhante, quando comparamos os dois grupos (artigos publicados até $2010 \mathrm{x}$ artigos publicados entre 2011 e 2020), encontramos diferenças marcantes e, nesse caso, uma diversidade, que demonstra a riqueza conceitual e teórica pelas quais a Revista Ciência \& Saúde
Coletiva contemplou seus leitores ao longo dos últimos 25 anos.

No $1^{\circ}$ grupo, artigos publicados até 2010 , a "teoria donabediana de avaliação de estrutura/ processo/resultado ${ }^{14 "}$, com $29,4 \%$ dos manuscritos representou a categoria com maior destaque. Já no grupo de textos publicados entre 20112020, a teoria de Billings ${ }^{15}$, sobre Ambulatory Care Sensitive Conditions (ACSC) e a teoria dos atributos da APS de Starfield ${ }^{16}$ representaram cada uma, $18,5 \%$ do total de artigos, seguidos também empatados com $15,4 \%$ por "avaliações normativas" e "teoria de avaliação de estrutura/ processo/resultados" (Tabela 3 ).

Do ponto de vista metodológico, a maior parte dos estudos considerou abordagem predominantemente quantitativa. Dois eixos distinguiram-se entre os períodos analisados (antes e depois de 2010), isto é, a grande pulverização de tipologias de avaliação esteve mais presente nos primeiros anos de publicação da revista.

Já o período posterior teve elevada concentração de artigos que, por um lado enfatizaram o uso de indicadores de atenção primária rela-

Tabela 3. Revisão bibliográficas sobre avaliação e atenção primária à saúde segundo teoria predominante abordada no texto. Revista Ciência \& Saúde Coletiva, 1996-2020 ( $\mathrm{n}=65)$.

\begin{tabular}{|c|c|c|c|c|c|c|}
\hline \multirow[b]{2}{*}{ Teoria predominante nos artigos } & \multicolumn{2}{|c|}{ Até 2010} & \multicolumn{2}{|c|}{ 2011-2020 } & \multicolumn{2}{|c|}{ Total } \\
\hline & $\begin{array}{c}\mathbf{n}^{\circ} \text { de } \\
\text { artigos }\end{array}$ & $\%$ & $\begin{array}{l}\mathrm{n}^{\circ} \mathrm{de} \\
\text { artigos }\end{array}$ & $\%$ & $\begin{array}{l}\mathbf{n}^{\circ} \text { de } \\
\text { artigos }\end{array}$ & $\%$ \\
\hline $\begin{array}{l}\text { 01. Avaliação normativa (diversas referências citadas no } \\
\text { Quadro 1) }\end{array}$ & 0 & 0,0 & 10 & 20,8 & 10 & 15,4 \\
\hline 02. Análise político-institucional ${ }^{12,24}$ & 0 & 0,0 & 2 & 4,2 & 2 & 3,1 \\
\hline 03. Análise exploratória qualitativa ${ }^{25}$ & 1 & 5,9 & 3 & 6,3 & 4 & 6,2 \\
\hline 04. Teoria da avaliação e implantação de programas ${ }^{26,27}$ & 2 & 11,8 & 1 & 2,1 & 3 & 4,6 \\
\hline 05. Triângulo de Governo de Matus ${ }^{28}$ & 0 & 0,0 & 1 & 2,1 & 1 & 1,5 \\
\hline 06. Teoria da Avaliação de Impacto em Políticas Públicas ${ }^{29}$ & 1 & 5,9 & 0 & 0,0 & 1 & 1,5 \\
\hline $\begin{array}{l}\text { 07. Teoria da complexidade dos sistemas de saúde: as } \\
\text { quatro lógicas existentes }{ }^{30}\end{array}$ & 1 & 5,9 & 0 & 0,0 & 1 & 1,5 \\
\hline 08. Teoria da Avaliação e uso de modelo lógico ${ }^{26}$ & 1 & 5,9 & 1 & 2,1 & 2 & 3,1 \\
\hline 09. Avaliação descritiva da situação local de situação ${ }^{31}$ & 1 & 5,9 & 0 & 0,0 & 1 & 1,5 \\
\hline 10. Teoria da avaliação de estrutura/ processo/ resultado ${ }^{14}$ & 5 & 29,4 & 5 & 10,4 & 10 & 15,4 \\
\hline $\begin{array}{l}\text { 11. Teoria da Gestão Clínica em Atenção Primária à } \\
\text { Saúde }^{32}\end{array}$ & 0 & 0,0 & 1 & 2,1 & 1 & 1,5 \\
\hline 12. Teoria sobre acesso e utilização dos serviços de saúde ${ }^{33}$ & 0 & 0,0 & 1 & 2,1 & 1 & 1,5 \\
\hline $\begin{array}{l}\text { 13. Teoria de Billings }{ }^{15} \text {, sobre Ambulatory Care Sensitive } \\
\text { Conditions (ACSC). }\end{array}$ & 0 & 0,0 & 12 & 25,0 & 12 & 18,5 \\
\hline 14. Teoria dos atributos da Atenção Primária à Saúde (APS) ${ }^{16}$ & 2 & 11,8 & 10 & 20,8 & 12 & 18,5 \\
\hline $\begin{array}{l}\text { 15. Teoria Epidemiológica, estudos agregados - ecológicos } \\
\text { e estudos de base populacional }{ }^{34}\end{array}$ & 3 & 17,6 & 1 & 2,1 & 4 & 6,2 \\
\hline Total & 17 & 100,0 & 48 & 100,0 & 65 & 100,0 \\
\hline
\end{tabular}

Fonte: Elaboração própria. 


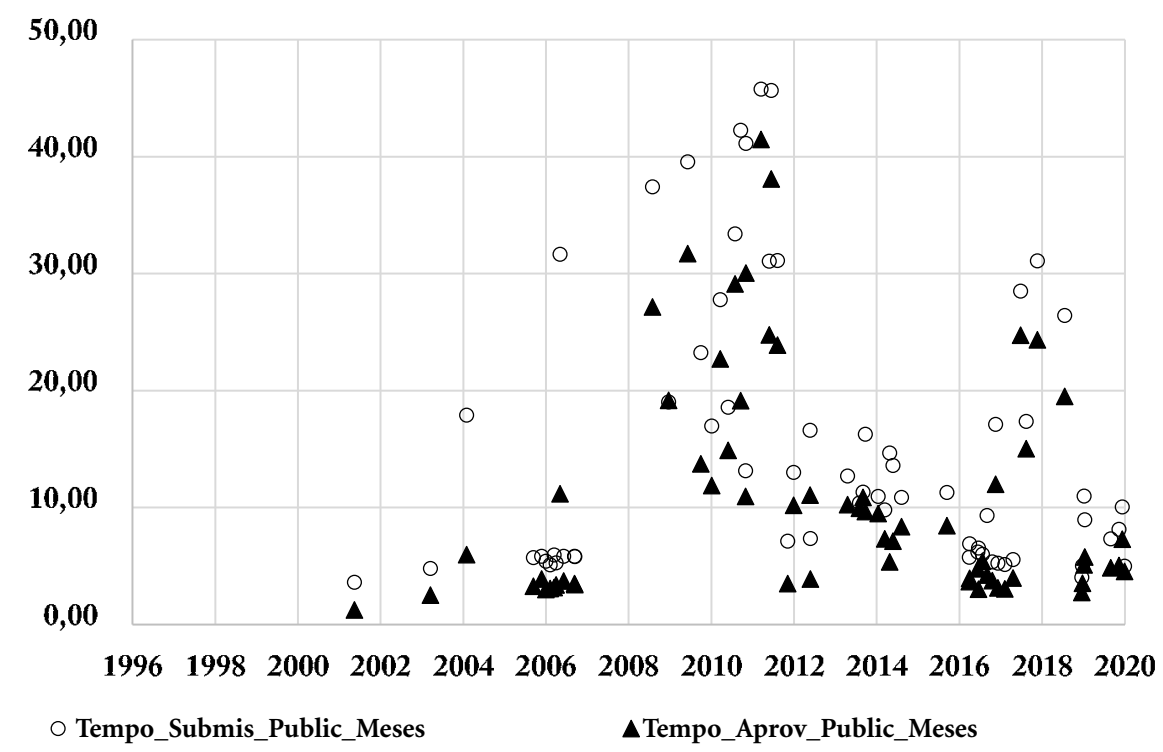

Gráfico 3. Distribuição do tempo de submissão, aprovação e publicação dos artigos sobre avaliação e atenção primária à saúde. Revista Ciência \& Saúde Coletiva, 1996-2020 (n = 65).

Fonte: Elaboração própria.

cionados às internações por condições sensíveis à atenção primária (ICSAP). Devemos lembrar que o Ministério da Saúde lançou uma consulta pública que posteriormente se tornou uma Portaria ${ }^{17}$ com a lista brasileira de condições sensíveis de atenção básica ${ }^{18}$. Seu uso e disseminação no Brasil é facilitado pelas décadas de existência do Sistema Informações Hospitalares (SIH-SUS) que agrega mensalmente as internações ocorridas pelo Sistema Único de Saúde (SUS) e as disponibiliza sob a forma de microdados não identificados nominalmente no site do Departamento de Informática do SUS (DATASUS).

Por outro lado, também contribuiu para a publicação dos artigos na Revista Ciência \& Saúde Coletiva o uso do instrumento de avaliação dos atributos da APS proposto originalmente por Shi e Starfield ${ }^{19}$ e validado estatisticamente no Brasil pela própria Starfield (que esteve em 2002 na ENSP/Fiocruz para lançamento de seu livro seminal) e um grupo de pesquisadores da UFRGS $^{20}$. Esse instrumento, inclusive foi referendado pelo Ministério da Saúde do Brasil que publicou em 2010 o Manual do chamado con- junto de instrumentos "PCATool-Brasil"21. Esse Manual pode ser considerado como um divisor de águas para a Avaliação em Saúde e Atenção Primária, na medida em que possibilitou a capilarização nacional de uma metodologia de pesquisa avaliativa, considerando a experiência de usuários, gerentes e profissionais dos serviços de saúde. Podemos destacar inclusive uma versão brasileira desse instrumento validada para Saúde Bucal, tanto para usuários como para cirurgiõesdentista $^{22,23}$.

Nos estudos internacionais publicados pela Revista estão mais presentes a avaliação de indicadores de desempenho clínico-epidemiológicos, assim como as avaliações normativas, em particular, no caso de Portugal, com todo o arcabouço legal de seu Sistema Nacional de Saúde (SNS).

\section{Tempo de submissão, aprovação e publicação dos artigos}

Um dos indicadores utilizados para medir a qualidade de uma revista científica na base da Web of Science (WoS) é o tempo de publicação 
dos artigos submetidos. Para responder a essa questão, medimos o tempo (em meses), incluindo ainda, o período de aprovação do artigo. Isto é, construímos duas variáveis: tempo entre a submissão e publicação do artigo e, tempo entre a aprovação e publicação do mesmo.

Os dados evidenciam a grande queda de ambos os indicadores ao longo dos últimos 25 anos, em particular, a partir do ano de 2011, quando a Revista Ciência \& Saúde Coletiva passou a ser editada mensalmente. Contudo, ainda encontramos alguns artigos que levaram mais de 12 meses entre o tempo de submissão e publicação e entre o tempo de aprovação e publicação (Gráfico 3).

\section{Considerações Finais}

No período de 1996-2020, para os artigos publicados na Revista Ciência \& Saúde Coletiva, a maior parte dos autores não distinguiu conceitualmente a "atenção básica" da "atenção primária à saúde". Ou seja, retomando uma de nossas perguntas iniciais, a maioria dos autores considerou como sinônimos esses dois termos, pelo menos até 2015. Nesse artigo, contudo, definimos a atenção primária à saúde no Brasil como aquela que é prestada exclusivamente pelas Equipes de Saúde da Família (eSF), pois são esses os profissionais de saúde que tem por missão desenvolver os atributos de Starfield enunciados desde a primeira versão da Política Nacional de Atenção Básica (PNAB) ainda em $2006^{35}$ e que foram radicalizados como o novo modelo de financiamento federal enunciado em 2019 que previu o monitoramento e a avaliação individual de cada eSF, considerando como unidade de análise, o indivíduo. Isto é, pela primeira vez na história da saúde pública do Brasil, os dados coletados de cada pessoa - clínicos e epidemiológicos -, passaram a ser registrados para gerar indicadores de base populacional e, o Ministério da Saúde começou transferir uma parte dos recursos financeiros fundo-a-fundo para os municípios com critérios por capitação ${ }^{36}$.

Quanto à outra pergunta inicial que fizemos, a criação da Secretaria de Atenção Primária à Saúde (SAPS) - comandada inicialmente por um médico de família -, no âmbito do Ministério da Saúde em 2019, nosso estudo aponta que um maior número de autores da Revista começa a concentrar um maior uso do termo "atenção primária à saúde" em detrimento de "atenção básica à saúde”. O último número temático especial da Revista Ciência \& Saúde Coletiva, de abril de
2020, já demonstra esse fato além da evolução do número de artigos publicados nessa direção nos últimos cinco anos.

Os limites das amostras constituem uma questão recorrente que influenciam nos resultados. Vários autores apontam possíveis vieses quanto ao fato de se ter amostra de voluntários ou de colaboradores que desejaram participar ${ }^{37}$ e não representam adequadamente a população de cada estudo. Sobre esses aspectos as pesquisas amostrais domiciliares ainda são muito tímidas no Brasil e especialmente desenvolvidas pelo Instituto Brasileiro de Geografia e Estatística (IBGE) que desde a década de 1980 inclui ou em suplementos especiais, ou em inquéritos específicos, como as Pesquisa Nacionais de Saúde (PNS), módulos que permitem avaliar o desempenho dos serviços de saúde no Brasil. A inovação mais recente nesse sentido, foi a inclusão de um Módulo que permite avaliar a atenção primária à saúde no Brasil, regiões e unidades da federação, com amostra probabilística domiciliar. Estamos nos referindo à PNS-2019 com o conjunto de questões do PCATool - versão reduzida usuário adulto, que foi incluída no instrumento de coleta de dados ${ }^{38}$. Nesse sentido, uma recomendação é fazer o que vários países do mundo já fazem como o Reino Unido e o Canadá que regularmente incluem em suas pesquisas domiciliares (respectivamente a Health and Lifestyle Survey e a Canadian Community Health Survey) um conjunto de questões que permitem a avaliação de seus serviços de saúde, inclusive no âmbito da atenção primária ${ }^{39,40}$.

No aniversário de 25 anos da Revista Ciência \& Saúde Coletiva, fica evidenciado que o papel indutor do Ministério da Saúde na definição de políticas/consultas públicas e instrumentos de avaliação esteve fortemente associado à publicação dos artigos no período aqui estudado. Em 2020, a publicação do novo Manual do conjunto de instrumentos que compõem PCATool-Brasil pelo Ministério da Saúde ${ }^{41}$ deverá induzir a uma nova onda de estudos e pesquisas com o uso desse instrumento, ampliando o escopo inicial de avaliação dos serviços de atenção primária à saúde para avaliações de base domiciliar populacional, inaugurada pelo IBGE em sua Pesquisa Nacional de Saúde (PNS-2019). Nessa direção, considerando uma abordagem estatístico-epidemiológica, o futuro da avaliação em APS poderá caminhar para indicadores de base populacional (via prontuário eletrônico) e monitoramento de cada uma das Equipes de Saúde da Família no país, com o uso de um número de identificação 
única (CPF) e gestão mensal inédita de "registros duplicados", vinculados à parte das transferências federais da APS para os municípios, definidos pelo Ministério da Saúde em 2019. Caminhando nessa direção talvez o Brasil consiga calcular na APS, indicadores intermediários e finalísticos sob a perspectiva clínica e epidemiológica, tal como os cuidados primários em saúde de Portugal, Espanha e Reino Unido o fazem há mais de 10 anos.

\section{Colaboradores}

LF Pinto desenvolveu pesquisa sobre avaliação e atenção primária à saúde, gerando como parte dessa, a elaboração do artigo, como parte de seu estágio de pós-doutorado no Instituto de Higiene e Medicina Tropical (IHMT), da Universidade Nova de Lisboa, Portugal. ZMA Hartz revisou criticamente o texto e o aprovou. 


\section{Referências}

1. Starfield B. Primary Care: Concept, Evaluation, and Policy. New York: Oxford University Press; 1992.

2. Oliveira ES. Assistência médico-sanitária: notas para uma avaliação. Cad Saude Publica 1991; 7(3):370-395.

3. Macinko J, Harris MJ. Brazil's Family Health Strategy - Delivering Community-Based Primary Care in a Universal Health System. N Engl J Med 2015; 372(23):2177-2181.

4. Brasil. Ministério da Saúde (MS). Cadastro Nacional de Estabelecimentos de Saúde (CNES) [Internet]. Brasília: DATASUS/Secretaria Executiva; 2020 [acessado 2020 Jun 25]. Disponível em: http://cnes2.datasus. gov.br/Mod_Ind_Unidade.asp?VEstado $=00$

5. Brasil. Ministério da Saúde (MS). Portaria GM/MS $\mathrm{n}^{\circ} 188$, de 3 de fevereiro de 2020. Declara Emergência em Saúde Pública de importância Nacional (ESPIN) em decorrência da infecção humana pelo novo coronavírus (2019-nCoV). Diário Oficial da União 2020; 4 fev.

6. Instituto Brasileiro de Geografia e Estatística (IBGE). Pesquisa Nacional por Amostra de Domicílios Contínua (PNAD) COVID-19. Microdados. Coordenação de Rendimentos (COREN), Diretoria de Pesquisas. Rio de Janeiro: IBGE; 2020.

7. Hartz ZMA, Pouvourville G. Avaliação dos Programas de Saúde: a eficiência em questão. Cien Saude Colet 1998; 3(1):68-82.

8. Hartz ZMA. Avaliação dos programas de saúde: perspectivas teórico-metodológicas e políticas institucionais. Cien Saude Colet 1999; 4(2):341-354.

9. Bodstein R. Atenção básica na agenda da saúde. Cien Saude Colet 2002; 7(3):401-412.

10. Costa NR, Pinto LF. Avaliação de programa de atenção à saúde: incentivo à oferta de atenção ambulatorial e a experiência da descentralização no Brasil. Cien Saude Colet 2002; 7(4):907-923.

11. Assis M, Hartz ZMA, Valla VV. Programas de promoção da saúde do idoso: uma revisão da literatura científica no período de 1990 a 2002. Cien Saude Colet 2004; 9(3):557-581.

12. Reis JG, Harzheim E, Nachif MCA, Freitas JC, D’Ávila O, Hauser L, Martins C, Pedebos LA, Pinto LF. Criação da Secretaria de Atenção Primária à Saúde e suas implicações para o SUS. Cien Saude Colet 2019; 24(9):3457-3462.

13. Brasil. Ministério da Saúde (MS). Portaria GM/MS no 3.222, de 10 de dezembro de 2019. Dispõe sobre os indicadores do pagamento por desempenho, no âmbito do Programa Previne Brasil. Brasília: Ministério da Saúde, 2019b. Diário Oficial da União 2019; 11 dez.

14. Donabedian A. The seven pillars of quality. Arch Pathol Lab Med 1990; 114(11):1115-1118.

15. Billings J, Teicholz N. Uninsured patients in District of Columbia hospitals. Health Affairs 1990; 9(4):158165.

16. Starfield B. Atenção primária: equilíbrio entre necessidades de saúde, serviços e tecnologia. Brasília: Unesco, MS; 2002.
17. Brasil. Ministério da Saúde (MS). Portaria MS/GM n ${ }^{\circ}$ 221, de 17 de abril de 2008. Publica, na forma do anexo desta portaria, a lista brasileira de internações por condições sensíveis à atenção primária. Diário Oficial da União 2008; 18 abr.

18. Alfradique ME, Bonolo PF, Dourado I, Lima-Costa MF, Macinko J, Mendonça CS, Oliveira VB, Sampaio LFR, De Simoni C, Turci MA. Internações por condições sensíveis à atenção primária: a construção da lista brasileira como ferramenta para medir o desempenho do sistema de saúde (Projeto ICSAP - Brasil). Cad Saúde Pública 2009; 25(6):1337-1349.

19. Shi L, Starfield B, Xu J. Validating the adult primary care assessment tool. J Fam Pract 2001; 50(2):161-164.

20. Harzheim E, Starfield B, Rajmil L, Álvarez-Dardet C, Stein AT. Consistência interna e confiabilidade da versão em português do Instrumento de Avaliação da Atenção Primária (PCATool-Brasil) para serviços de saúde infantil. Cad Saude Publica 2006; 22(8):16491659.

21. Brasil. Ministério da Saúde (MS). Manual do instrumento de avaliação da atenção primária à saúde: Primary Care Assessment Tool - PCATool-Brasil. Brasília: MS; 2010.

22. Fontanive LT. Adaptação do instrumento Primary Care Assessment Tool - Brasil versão usuários dirigido à Saúde Bucal [dissertação]. Porto Alegre: Universidade Federal do Rio Grande do Sul; 2011.

23. D’Avila OP. Avaliação de Serviços de Saúde Bucal na Atenção Primária a Saúde: análise conceitual, psicométrica e exploratória [tese]. Porto Alegre: Universidade Federal do Rio Grande do Sul; 2016.

24. Biscaia AR, Heleno LCV. A Reforma dos Cuidados de Saúde Primários em Portugal: portuguesa, moderna e inovadora. Cien Saude Colet 2017; 22(3):701-712.

25. Minayo MCS. Pesquisa social: teoria, método e criatividade. $22^{\mathrm{a}}$ ed. Rio de Janeiro: Vozes, 2003.

26. Hartz ZMA. Avaliação em saúde: dos modelos conceituais à prática na análise da implantação de programas. Rio de Janeiro: Editora Fiocruz; 1997

27. Contandriopoulos AP, Champagne F, Denis JL, Pineault R. A avaliação na área da saúde: conceitos e métodos. In: Hartz ZAM, organizadora. Avaliação em saúde: dos modelos conceituais à prática na análise da implantação de programas. Rio de Janeiro: Editora Fiocruz; 1997.

28. Matus C. Estrategia y plan. Santiago de Chile: Editorial Universitaria; 1972.

29. Draibe SM. Avaliação de implementação: esboço de uma metodologia de trabalho em políticas públicas. In: Barreira MCR, Carvalho MCB, organizadores. Tendências e perspectivas na avaliação de políticas e programas sociais. São Paulo: IEE/PUC; 2004. p. 15-42.

30. Contandriopoulos AP. Avaliando a institucionalização da avaliação. Cien Saude Colet 2006; 11(3):705-711.

31. Testa M. O diagnóstico de saúde. In: Rivera FJU, organizador. Planejamento e programação em saúde: um enfoque estratégico. 2a ed. São Paulo: Editora Cortez; 1992. 
32. Wagner ECK. Guiding Transformation: How Medical Practices Can Become Patient Centered Medical Homes. New York: The Commonwealth Fund; 2012.

33. Andersen RM. Revisiting the behavioral model and access to medical care: does it matter? J Health Soc Behav 1995; 36(1):1-10.

34. Medronho RA, Bloch KV, Luiz RR, Werneck GL, editores. Epidemiologia. 2a ed. São Paulo: Editora Atheneu; 2009.

35. Brasil. Ministério da Saúde (MS). Portaria/MS no 648, de 28 de março de 2006. Aprova a Política Nacional de Atenção Básica (PNAB), estabelecendo a revisão de diretrizes e normas para a organização da Atenção Básica para o Programa Saúde da Família (PSF) e o Programa Agentes Comunitários de Saúde (PACS). Diário Oficial da União 2006; 28 mar.

36. Harzheim E, D'Avila OP, Ribeiro DC, Ramos LG, Silva LE, Santos CMJ, Costa LGM, Cunha CRH, Pedebos LA. Novo financiamento para uma nova Atenção Primária à Saúde no Brasil. Cien Saude Colet 2020; 25(4):1361-1374.

37. Ruffing-Rahal MA. Evaluation of group health promotion with community-dwelling older women. $P u$ blic Health Nursing 1994; 11(1):38-48.

38. Instituto Brasileiro de Geografia e Estatística (IBGE). Pesquisa Nacional de Saúde (PNS). Coordenação de Rendimentos (COREN). Diretoria de Pesquisas. Rio de Janeiro: IBGE; 2020.

39. Office for National Statistics. Health and Lifestyle Sur$v e y$ [Internet]. United Kingdom; 2020 [acessado 2020 Jun 25]. Disponível em: https://www.ons.gov.uk/ surveys/informationforhouseholdsandindividuals/ householdandindividualsurveys/healthandlifestylesurveyhls

40. Statistics Canada. Canadian Community Health Survey (CCHS) [Internet]. Ottawa; 2020 [acessado 2020 Jun 25]. Disponível em: https://www23.statcan.gc.ca/ imdb/p2SV.pl?Function=getSurvey\&SDDS=3226

41. Brasil. Ministério da Saúde (MS). Secretaria de Atenção Primária à Saúde. Departamento de Saúde da Família. Manual do Instrumento de Avaliação da Atenção Primária à Saúde: PCATool-Brasil - 2020. Brasília: MS; 2020.

Artigo apresentado em 10/07/2020

Aprovado em 13/07/2020

Versão final apresentada em 15/07/2020 